\title{
LA TEORIAA DE LA ELIPSIS EN FRANCISCO SÁNCHEZ DE LAS BROZAS: ¿UNA ANTICIPACIÓN DE LA GRAMÁTICA GENERATIVA?
}

\author{
Stefano Arduini \\ Universidad de Bolonia
}

Cuando una teoria de algún modo innovadora se impone en la comunidad cientifica de una disciplina determinada, produce normalmente ciertos intereses, discusiones e incluso cambios en las disciplinas más diversas, según un movimiento de ondas concéntricas que afecta directa y más intensamente a las áreas próximas $y$ va disminuyendo paulatinamente a medida que nos alejamos del área de estudio originaria (1). Tal expansión tiene, como contrapartida, una cierta influencia también

(1) Con esto no quiero dar, naturalmente, ninguna ley general; solamente digo que con frecuencia observamos de modo empírico tal difusión por ondas concéntricas en campos muy diversos; piénsese, por ejemplo, en la expansión de la teoría de la relatividad, del psicoanálisis y del estructuralismo, expansión tan fuerte que ha visto a veces cómo disciplinas colindantes han recibido estímulos y sugerencias de las tres "teorias" al mismo tiempo (son ampliamente conocidos los enlaces entre estructuralismo y psicoanálisis, especialmente en el ámbito francés). 
en el campo de origen (aquél desde el que la teoría inició su difusión), descubriendo horizontes inéditos, vivificando ramas secas y dando una nueva autonomía a aquellas secciones consideradas secundarias. También con la gramática generativa de Noam Chomsky hemos tenido un proceso semejante. En particular Chomsky ha funcionado como agente provocador de un renacido y dinámico interés por la historia de nuestra disciplina, por aquella historia de la lingüística que en los últimos quince años ha producido un conjunto de notables intervenciones en numerosas direcciones (2). No es, pues, casual que en cierto número de trabajos pertenecientes a este área de investigación circule el nombre de Chomsky en cierto modo como el holandés errante circulaba por los mares del mundo, apareciendo en los momentos y en los lugares más inesperados: de Wittgenstein a Ockham, de Descartes a Aristóteles, de Port Royal a la gramática renacentista (3). De todos modos, es cierto que Chomsky es, en este sentido, un punto de referencia importante y que en su lingüística cartesiana funciona como el centro alrededor del cual giran las polémicas. Por lo que a mí concierne, no podía prescindir de la presencia, explícita o implícita, de Chomsky (también porque no es posible eludir los problemas por él planteados) al considerar el papel de la gramática renacentista, estudiada aquí en la figura de uno de sus representantes más importantes: Francisco Sánchez de la Brozas. Es más, se verá cómo, incluso cuando me ocupe de un problema relativamente particular en el ámbito de la obra del Brocense - la elipsis - , las críticas que se levantarán a las diversas interpretaciones serán las mismas que, más en general, tienen a Chomsky como blanco (y esto a pesar de las diferencias que hay entre las lecturas chomskyanas y las de otros intérpretes). El de Chomsky es, pues, un tipo de acercamiento que ha creado escuela y que más allá de cada una de las interpretaciones estudia la historia de la lingüística en función de la gramática generativa (es bello e interesante sólo lo que en alguna medida es una anticipación de ella), perdiendo de vista con frecuencia el valor autónomo de muchas teorías lingüísticas del pasado (4).

(2) Esto no significa que anteriormente no estuviéramos interesados en la historia de la lingüística (si bien con frecuencia tal historia estaba limitada, y a veces lo está todavia, a la historia de la glotología, considerándose el año 1800 como punto de partida de la lingüística científica), pero Chomsky ha removido, $y$ esto es innegable, las aguas, dando nuevo oxígeno a las viejas discusiones.

(3) Considérense, a tal propósito, las representativas antologías de Parret, 1976, y JolyStéfanini, 1977.

(4) Legibles y muy aprovechables (piénsese en Pànini o en el primer gramático islandés) propiamente en cuanto son autónomas y no en cuanto son un simple apéndice de la modernidad en el pasado. 


\section{FRANCISCO SÁNCHEZ DE LAS BROZAS Y EL PROBLEMA DE LA GRAMÁTICA RENACENTISTA}

El motivo fundamental de la inmediata resonancia y del actual interés por la lingüística cartesiana de Chomsky (5) probablemente tiene que buscarse en la contribución dada al resurgimiento de la atención hacia los estudios sobre el lenguaje anteriores al siglo pasado, en el haber planteado claramente, en suma, la cuestión de la imposibilidad de establecer con certeza un inicio para una hipotética «lingüística científica» y en el haber subrayado la existencia de una serie de recorridos del pensamiento que sólo con dificultad podríamos interrumpir en una cierta fecha definiendo, aunque de modo convencional, un punto de partida (6). En realidad, Chomsky no ha mantenido después cuanto parecia prometer y su posición en el examen concreto de cada uno de los autores y períodos, al privilegiar la importancia de la gramática de Port Royal, ha terminado por confiar un papel secundario a gran parte de la producción siguiente (y representativa es, a este respecto, la cita de Whitehead) y anterior (la gramática humanístico-renacentista, por ejemplo). Naturalmente, hay que entender esto no en el sentido de que los estudios sobre el lenguaje anteriores y posteriores a la fecha de publicación de la Grammaire générale et raisonnée sean considerados irrelevantes, todo lo contrario - piénsese en el papel de Humboldt - , sino en el sentido de que la teorización de aquellos siglos tiene una función propia sólo en relación con el gran trabajo realizado en el siglo XVII (7); sucede así que todo lo que no pertenece al "genio del siglo XVIll» es concebido, bien como anticipación de Port Royal (Sánchez de las Brozas), bien como su consecuencia (la Enciclopedia, pero también en parte Humboldt) (8). Se han presentado muchas críticas a Chomsky, sobre todo insistiendo en la importancia de la tradición empirista de Locke (Aarsleff, 1970; id. 1971; id. 1974) y, más en general, en la necesidad de una mayor profundidad y una más atenta consideración de las fuentes. De particular interés es la posición de Luigi Rosiello, quien en diversos trabajos (cfr. Rosielio,

(5) Incluso con todas las críticas a que esta actitud puede ser sometida; cfr. Aarsleff, 1970; id., 1971; Miel, 1969; Rosiello, 1967; Bracken, 1972; Dorstet, 1972; Uitti, 1969-1970.

(6) Cfr. Chomsky, 1977; Rosiello, 1967.

(7) Del mismo modo que éste tiene importancia sólo en función de la gramática generativo-transformacional; como se ve, se trata de una concepción sensiblemente tèleológica.

(8) Con esto no pretendo decir que Chomsky lleve a cabo esta desvalorización voluntariamente, sino que tal es el resultado implícito de su falta de relativismo histórico. Para una interpretación del Brocense en ese sentido chomskyano, cfr. Otero, 1973; Moreau, 1967. 
1967; id. 1979a; id. 1979b) ha estudiado con profundidad las teorías lingüísticas de la llustración llegando a conclusiones opuestas en muchos aspectos a las de Chomsky y reconociendo a la lingüística de la Ilustración toda su importancia y originalidad (9). Análogamente, a propósito de la gramática humanístico-renacentista se ha hecho y se va haciendo con gran atención algo semejante (10), pero es necesario profundizar mucho en la materia y aciarar la contribución de los principales autores de este perído; hace falta sobre todo, dejada a un lado toda filosofía de la anticipación, examinar en qué sentido los estudios de este periodo sobre el lenguaje revestían en la época un cierto interés y cómo podemos estudiarlos hoy.

Un trabajo de esa índole, un estudio global de la lingüística renacentista, podría dejar claro un resultado que se entrevé ya en diversas intervenciones sobre los diferentes autores del período, me refiero al reconocimiento de la originalidad y autonomía de los estudios lingüísticos del Humanismo y del Renacimiento (11), de este período que vio a gramáticos, filólogos y filósofos ocupados en un trabajo verdaderamente extraordinario de revisión teórica en torno a los problemas concernientes al lenguaje.

Entre los hombres que contribuyeron al remozamiento de la cultura tradicional, en aquel arco de tiempo extremamente fluctuante para los historiadores, pero en el cual haremos entrar por razones de claridad los siglos XV y XVI, Francisco Sánchez de las Brozas fue sin duda un representante típico de la "vanguardia intelectual» de la época. Una época que en el plano de la teorización lingüística podrá reservar notables sorpresas al investigador moderno.

(9) «Nella storia del pensiero linguistico... il settecento illuminista segna un momento cruciale in cui si spezza quella tredizione di ontologismo logico che faceva corrispondere le categorie grammaticali alle categorie del pensiero e quindi all'ordine razionale della realtà. Nell'assumere le varie realtà linguistiche come fatti empiricamente e storicamente definibili, il pensiero illuminista apre la strada all'instaurazione della linguistica come scienza empirica e agli sviluppi che essa avrà nel secolo decimonono» (Rosiello, 1979a, pág. 263).

(10) Cfr. R. Lakoff, 1969; Breva Claramonte, 1977; id., 1978a; id., 1978b; id., 1980a; id. 1980b; Michelena, 1975; Percival, 1976; Viljamaa, 1976. Más en general cfr. Padley, 1976 y las compilaciones cuidadas por Joly-Stéfanini, 1977 y Parret, 1976.

(11) Originalidad y autonomía en el área de la teoría del lenguaje ( $y$ en todo caso sin excluir componentes heteronómicos sobre todo con respecto a la Edad Media), lo que no significa una toma de posición historiográficamente más amplia, donde se conocen las críticas, procedentes de más partes (en particular a la ciencia de los siglos $X V$ y XVI), al concepto mismo de Renacimiento y a su valor autónomo. Para la historia del problema, cfr. Prandi, 1971. 
Los motivos del proceso que llevó de la gramática medieval de tipo especulativo a aquélla en la que razón y experiencia son dos polos de igual importancia (la Minerva, por ejemplo) son múltiples y de difícil sistematización; podemos solamente intentar, aunque sólo sea por tener un cuadro general del período, resumirlos brevemente. En primer lugar, el desarrollo del conocimiento $y$ análisis del árabe y sobre todo del hebreo tiene gran importancia (12); el "homo trilinguis» (griego, latín y hebreo), ideal renacentista del hombre de cultura, es un ejemplo elocuente del relieve totalmente nuevo asumido por la lengua bíblica (13); pueden verse a este propósito las gramáticas de Reuchlin (1506) y Clenard (cfr. Robins, 1974, pág. 99). No por casualidad puede sostener Jacques Dubois (Silvio) en su /sagóge la derivación de la «declinación» francesa a partir de la hebrea. No hay que olvidar tampoco al autor del que nos estamos ocupando, el Brocense, cuya división tripartita de la "oratio" ha sido considerada (si bien hoy se tiende a negar tal posibilidad) de origen árabe y hebreo (14), hipótesis sostenida tanto por Delbrück (Delbrück, 1983 l, pág. 16) como por Wackernagel (Wackernagel, $1950 \mathrm{I}$, pág. 23) y contradictoriamente recogida por Pagliaro (Pagliaro, 1930, págs. 33-34), Tovar (Tovar, 1941, pág. XLIII), Bassols (Bassols, 1946, pág. 50). Por lo demás, el propio Brocense escribe: "Sunt autem tria, nomen, verbum, particulae. Nam apud Hebraeos tres sunt partes orationis, nomen, verbum et dictio consignificant. Arabes quoque has tantum tres orationis partes habent) (libro I, capitulo $2 \%$. No es de la misma opinión Constantino García, quien defiende, en cambio, la raíz aristotélica de la teoría sanctiana:

Si la oración es la expresión de un juicio y éste consta funda-

(12) Robins justifica este interés con «el relajamiento de los vinculos clericales durante el Renacimiento" (Robins, 1974, pág. 99), pero esto no me convence demasiado; piénsese, por ejemplo, que precisamente éste es el período en el que nace la Inquisición española (y por consiguiente un organismo de control no sólo político sino también cultural) y en el que se lanzarán los ataques más severos contra las comunidades hebrea y árabe. En la acusación de la Inquisición de Madrid contra el Brocense se lee: «el tal reo es hereje, temerario, muy insolente, atrevido y mordaz como lo son todos los gramáticos $y$ erasmistas) (Proceso original que la Inquisición de Valladolid hizo al maestro Francisco Sánchez de las Brozas, en Documentos inéditos para la Historia de España, Madrid, 1843; reedición, Vaduz, 1964, págs. 5-170). Cłr. también Tovar-De la Pinta Llorente, 1941.

(13) La importancia del hebreo se mantendrá hasta todo el siglo XVIII e incluso más tarde; véase, por ejemplo, Fabre d'Olivet, La langue hébräque restituée et le véritable sens des mots hébreux, 1815. Cfr. Kukenheim, 1951; Lázaro, 1949; Arens, 1975; Padley, 1976.

(14) Pero véase también Merril, 1970, con un análisis bastante útil sobre el resurgimiento, después de la tradición griega, árabe y hebrea, de la clasificación tripartita de la oración. 
mentalmente de sujeto y predicado, que identifica con nombre $y$ verbo, y añadimos a ellos, en vez de la palabra de enlace aristotélica, las partículas, tenemos la coincidencia del Brocense con el Estagirita. (C. García, 1961, pág. 82).

Me resulta difícil, personalmente, dar un juicio preciso; sin duda parece más obvio pensar en un préstamo aristotélico que en uno árabe o hebreo, piıes a fin de cuentas la tradición clásica resulta más próxima que la oriental, pero haría falta ver si esto era igualmente obvio para el Brocense (15).

Un segundo punto que podría caracterizar el paso a la cambiada perspectiva de la gramática renacentista es el interés, del todo nuevo, por la latinidad y el deseo de una vuelta, lo más pura posible, a aquélla; sesgo intelectual éste que acompaña a las nuevas posibilidades de estudio del griego debidas a la expatriación de los maestros griegos después de la caída de Constantinopla (16). La filología recibió un empuje enorme de tal situación (17); en el campo gramatical nacieron, por otra parte, una serie de obras originales caracterizadas por el retorno riguroso a la «latinitas» y por el desprecio hacia todo lo que recordase la Escolástica (18). Los autores que pueden ser de utilidad en relación con el Brocense

(15) Constantino García sostiene, además, que el Brocense no hace ninguna otra mención del árabe en su obra. En mi examen de las Opera omnia de Sánchez de las Brozas (edición de Mayáns y Siscar, Ginebra, 1766), dirigido en principio precisamente a investigar estas posibles influencias, no he conseguido encontrar algo que no sea el uso obvio y continuo de tales lenguas en las Etimologías. Del mismo parecer es Liaño Pacheco, 1971, pág. 85: «Antes de terminar este capítulo debemos insinuar, al menos, que estamos conformes con la opinión de Constantino García al no admitir ningún influjo ni de la gramática árabe ni de la hebrea en la división que el Brocense hace de las partes de la oración... No le hacia falta por otra parte mucho conocimiento de las lenguas semitas para saber, en contacto con Profesores de la Universidad de Salamanca, que en esas lenguas sólo consideran los gramáticos tres partes de la oración». Es necesario, sin embargo, recordar que la gramática hebrea de Reuchlin, que divulgaba en Europa el uso de una clasificación diferente por parte de los gramáticos hebreos, es ochenta y un años anterior a la Minerva; cfr. también Bell, 1925.

(16) Cfr. Geanakoplos, 1967.

(17) Sobre el nuevo interés por la latinidad y el consiguiente nacimiento del método filológico, cfr. Sabbadini, 1922.

(18) Cfr. Kukenheim, 1932; Arens, 1975; Padley, 1976; Apel, 1963 (la obra de Apel es muy importante para todas las cuestiones lingüisticas del Renacimiento y créo que en ella se pueden encontrar notables temas de interés que pueden ser desarrollados ulteriormente; desagrada solamente que sea tan poco citada - lo cual es debido con toda probabilidad a su posición filosófica - en los trabajos de historia de la linguïstica. 
son: Valla, Scalígero y, en el ámbito español, Vives y Nebrija (19). Lorenzo Valla (20) fue el maestro de la resurgida latinidad, fue el que se revolvió contra el estado de decadencia en que estaba abandonada la lengua latina y subrayó la importancia de devolver aquella lengua célebre y casi reina (como dice en el prológo de las Elegantiae) al estado original, exigencia ésta que no era un fin en sí misma, sino que hallaba su significado profundo en el uso que del latín hacian otras disciplinas fundamentales: por ejemplo, el derecho y la lógica; y si la metodología presente en las Dialecticae disputationes estaba «destinata a trasformare la modesta pratica grammaticale in uno strumento estremamente efficace di critica speculativa e storica (C. Vasoli, 1968, pág. 40), con las Elegantiae (21) se ofrecen, a través de un examen minucioso de las «auctoritates» que recuerda en parte la Minerva, las reglas de oro del perfecto lenguaje clásico (del «bene loquendo»). Valla es citado por el Brocense numerosas veces, casi nunca positivamente (22); Sánchez Barrado (1919a; 1913b), y con él Constantino García, sostiene que tal oposición deriva del carácter estilístico más que gramatical de las observaciones vallianas $y$, añadiría yo por mi parte, procede de la continua confusión de los dos planos en la que incurre el humanista italiano; el Brocense, con su principio "Aliud est grammaticae, aliud latine loqui» (libro IV, último capítulo, respuesta a la primera objeción), no podría aceptar semejante modo de actuar. Pero es Julio César Scalígero (23), con su obra De causis linguae latinae (1540), el más directo antecedente sanctiano; el propio título escogido por el Brocense para su libro lo confirma: «At de linguae Latinae causis iam scripserat Caesar Scaliger, quem, quia in multis sequor, nonnumquam tamen ab eo disentiens, titulum non abisciendum putavi» (Minerva, libro $1,1^{\circ}$ ) ¿Cuál es la posición de Scalígero? Jean Stéfanini ha esbozado con agudeza unas líneas generales:

(19) No hay que olvidar, sin embargo, a Erasmo de Rotterdam, que tuvo gran importancia en el ámbito español (cfr. Bataillon, 1966; Abellán, 1976), ni a Linacre, considerado por Liaño como un importante antecedente para la teoría de la elipsis; cfr. T. Linacer, De emendata structura Latini sermonis Libri sex, Lyon, 1544; id., Grammatices, Lyon, 1546.

(20) Sobre Valla, cfr. Vasoli, 1968; Gaeta, 1955; Saitta, 1961-1962; Fois, 1979; Apel, 1963.

(21) Para las Elegantiae, que es quizá el texto más interesante con respecto al Brocense, no existe todavía hoy una edición crítica, y la bibliografía es casi inexistente; cfr. Marsh, 1979; Casacci, 1926. Cfr. tambien Percival, 1976 y Apel, 1963, págs. 235-236.

(22) Desde las primeras páginas de la Minerva; cfr. el prólogo dedicado a la Universidad de Salamanca.

(23) Sobre Julio César Scalígero cfr,, además naturalmente de las usuales obras generales, Apel, 1963; Stéfanini, 1976; Hall, 1950. 
Scaliger aborde son sujet en philosophe: les grammariens sont des sots, il le répète volontiers, mais le langage, lui, distingue l'homme de tous les autres êtres et permet seul l'exercise de la raison. Les lois de la grammaire s'imposent à la logique et à toutes les sciences. Or, rationaliste fervent, il croit à la toute-puissance de la raison et, par elle, au progrès: il sait que s'ouvrent des temps noveaux (Stéfanini, 1976, pág. 319).

Las leyes de la gramática se imponen a la lógica y a todas las ciencias, y las leyes de la gramática han de buscarse en la uratio» que hay en la base de la forma lingüística. Por otra parte el uso y los datos de los que éste es deducido tendrán gran importancia: razón y experiencia son también aquí, como en general para toda la gramática renacentista, los dos goznes sobre los que funcionará el método correcto de investigación lingüística (24).

En España las figuras más importantes, además del Brocense, son Vives y Nebrija. El interés que ofrece Juan Luis Vives (25) cubre un ámbito más general que el exclusivamente gramatical. No obstante, con su obra De causis corruptarum artium (1531) habia sido uno de los primeros que en España situaron la decadencia de las disciplinas en el mal estado en que se hallaban los estudios gramaticales; además, gran parté de su filosofía ( $y$ es por ésta por lo que Vives fue conocido en el extranjero) vio en el lenguaje un hecho importante en el estudio del hombre; esto es válido para muchas de sus obras: De explanatione cuiusque essentiae, Introductio ad sapientiam, la ya citada De causis corruptarum artium. En su tratado De anima et vita (1538), Vives uhace exclusivo de los seres humanos el lenguaje, que es tan natural al hombre como la razón... No entra de lleno en el problema del lenguaje, sino que solamente se refiere a él indirectamente en cuanto es manifestación de la razón o

(24) Sobre esta duplicidad se pueden adelantar diferentes hipótesis; en primer lugar, la doble influencia de Platón y Aristóteles. En el caso de Scaligero es cierta una influencia aristotélica, «En bon aristotélicien, il considére que le langage articulé est l'attribut de I'homme, c'est-à-dire qu'il est étroitement rattaché d'une part à la vie sociale (faut-il rappeler qu'Aristote a défini l'homme comme 'animal politique') et de l'autre à la raison humaine, ces deux caracteristiques n'en faisant qu' une dans la mesure où la société humaine est la seule à être l'effet, non du hasard (comme celles des fourmis), mais d'une volonté consciente et raisonnable» (Stéfanini, 1976, pág. 321).

(25) Sobre las teorias lingüisticas de Juan Luis Vives, cfr. Coseriu, 1977; sobre Vives en general cfr. Bonilla y San Martín, 1981; Ortega y Gasset, 1973; Manzoni, 1960; Guy, 1973; cfr. también Menéndez Pelayo, 1974, 1; García Berrio, 1977-1980, 11; Bell, 1944; Abellán, 1982. 
inteligencia del hombre» (C. García, 1961, pág. 39) (26). De todas formas, el antecedente directo en España de Sánchez de la Brozas es Elio Antonio de Nebrija (27), del cual se declara directo continuador. Será útil leer las palabras del Brocense con respecto a esto en la presentación de la Minerva:

lacebant itaque bonae litterae, quum abhinc annis centum noster Antonius Nebrissensis hos rebelles conatus est castigare. Sed adeo malum hoc radices egerat altas, ut innumeris monstris debellatis multo plura debellanda remanserit... Itaque quod ille non potuit tunc perficere, mihi forsitan perficiendum delegavit. (28).

Las dos obras principales de Nebrija son las Introductiones latinae (Salamanca, 1481) y la Gramática de la lengua castellana (Salamanca, 1492); en ambas se nos muestra un Nebrija más filólogo que lingüista. Las Introductiones son un método para enseñar bien el latín según un orden racional que se apoya en la «auctoritas» y semejante intención, pero vuelta al castellano, informa también la Gramática (29) (la primera obra en español que propone una gramática en lengua vulgar). Sin embargo, si bien el Brocense se declara explícitamente continuador de Nebrija, creo que tal afirmación debe ser aceptada sólo hasta cierto punto $y$ en el sentido de que el ilustre extremeño, aun partiendo de un origen común, sigue después caminos bastante diversos; es más, estoy plenamente de acuerdo con F. Riveras Cárdenas cuando afirma que el Brocense continúa la obra de Nebrija únicamente como perteneciente al mismo movimiento del viejo maestro:

(26) Importante es también el papel de Vives como humanista, por asi decirlo, militante y seguidor de Erasmo en España; si recordamos que una de las acusaciones dirigidas al Brocense por la Inquisición (véase la nota 12) era precisamente la de ser «hereje, temerario... como los son todos los gramáticos y erasmistas», se ve claramente cuál podía ser el papel de los continuadores de Erasmo en un momento de fuerte presión intelectual del aparato eclesiástico.

(27) Sobre Nebrija cfr. Miscelánea Nebrija, 1946; Abad, 1982; A. Alonso, 1949; Asensio, 1960; Bahner, 1966; Bassols de Climent, 1945; Casares, 1947; Fernández-Sevilla, 1974; Galindo Romeo-Ortiz Muñoz, 1946; Gili Gaya, 1947; González Llubera, 1927; Lapesa, 1981; Olmedo, 1942; Quilis, 1980; Rico, 1978.

(28) F. Sánchez de las Brozas continúa después explicando anecdóticamente los hechos que le han llevado a asumir esta tarea.

(29) La obra se divide en un Prólogo, donde encontramos los problemas teóricos, y en cinco libros: 1 . Partes de la Gramática y Ortografía; 2 . Prosodia y Silaba; 3 . Etimología (Partes de la "oration); 4. Sintaxis y Estilística; 5. Reglas para los extranjeros que aprenden el castellano. 
Las Introductiones Latinae y la Minerva representan dos métodos diversos de trabajo. Como indica Bassols de Climent, la actitud de Nebrija consiste en describir los fenómenos del lenguaje apoyándose en la autoridad de los grandes autores, mientras que el Brocense va a centrar su atención en la investigación de las causas que producen esos fenómenos. (Rivera Cárdenas, 1976, pág. 16).

La tercera marca distintiva de la lingüística renacentista ha de ser localizada en el estudio profundo de las lenguas nacionales. Hemos visto ya en España a Nebrija; para Francia se podría citar a Du Bellay con su Défense et illustration de la langue française (1549); a J. Dubois (Silvio), con su Isagoge; a Henri Estienne, con su Conformité du langage français avec le grec (1565); a A. Cauchie, con su Grammatica Gallica (1570); en Alemania la Reforma y la consiguiente versión de la Biblia desarrollaron una intensa problemática en torno a la lengua nacional (cfr. Rudolph Agricola); para Italia, la exposición sería demasiado compleja, baste en cualquier caso recordar las obras de Lorenzo de Medicis, de Pietro Bembo naturalmente, $y$ de Sperone Speroni. Este cambio de dirección tiene un valor que va más allá del simple significado gramatical, y que yo llamaría filosófico; refiriéndose al Humanismo italiano, pero en un sentido que abarca un horizonte más amplio, K.O. Apel escribe con gran claridad:

Non sussiste alcun dubbio che l'idea di lingua propria dell'umanesimo, quale nelle pagine precedenti abbiamo cercato di documentare nelle sue origini e nei suoi aspetti normativi, in Italia fu commista il piú intimamente possibile con la scoperta occidentale della madrelingua. L'umanesimo potenziale e l'apertura al latino come lingua formativa conferirono già all'instauratio dantesca del volgare una normatività su scala europea. Ed anche l'affermazione ideologica e interpretazione teoretica della madrelingua... sono riservate all'umanesimo... Allo stesso modo è solo il sotteraneo legame fra le aspirazioni degli italiani e il risveglio della lingua nazionale e della cultura italiane... a conferire all'umanesimo linguistico del Rinascimento una nuova spitiruale capacitá plasmatica in confronto all'umanesimo del Medio Evo (Apel, 1975, pág. 245) (30).

(30) Para toda la cuestión cfr. Apel, 1963, cap. 7. 
Un autor que en cierto modo resume todas las características vistas hasta ahora y que es importante tanto por el método general como por los análisis sobre lenguas concretas (el griego, el latín y una lengua vulgar, el francés) es Petrus Ramus, quien con dos abras sustancialmente paralelas, la Dialectique (1556) y la Gramere (1562), y con las Scholae Grammaticae (1595) se presenta como figura representativa para todo el Renacimiento, siendo doblemente interesante en tanto en cuanto junto a Scalígero y a Linacre forma la triada que ha influido de algún modo en el trabajo del Brocense (31). Con Ramus nos hallamos ante la propuesta de una gramática formal en la que será eliminada cualquier referencia al sentido en favor del simple funcionamiento abstracto de las formas; Chevalier (Chevalier, 1968) ha criticado este sistema tachándolo de ser capaz de realzar solamente algunas relaciones que señalan su funcionamiento; Robins ha resumido muy bien los principios que informan un trabajo de esta índole:

Ramus escribió gramáticas del griego, del latín y del francés, y dejó constancia de su teoría gramatical en su Scholae grammaticae. Mientras que en su gramática del francés aprovechó las referencias al latín como recurso didáctico, mostró, no obstante, su respeto por las características individuales de cada lengua. Más que seguir una argumentación gramatical de tipo filosófico, que según él no salvó a los escolásticos de los barbarismos, resaltó la importancia de observar y seguir el uso de los clásicos en lo que concierne a estas lenguas, $y$ a los hablantes nativos en las lenguas modernas. Sus descripciones y clasificaciones gramaticales se pueden considerar formales, ya que no se basan ni en la semántica ni en las categorias lógicas, sino en las relaciones existentes entre las formas reales de una palabra. (Robins, 1974, pág. 104).

\section{LA ELIPSIS SANCTIANA: ¿UNA ANTICIPACIÓN DE LA GRAMÁTICA GENERATIVA?}

Si los autores anteriores desempeñan un papel central en la definición epistemológica del estudio lingüistico y en la práctica concreta del análisis gramatical, la obra de Francisco Sánchez de las Brozas es, como ha sido anunciado al comienzo, igualmente importante y por muchos as-

(31) A propósito de las fuentes históricas es oportuno, en este punto, citar a Percival, 1971; cfr. además Hornedo, 1943. 
pectos crucial; este relieve se debe, bien a un interés intrínseco de sus propuestas teóricas, bien al hecho de haber sido considerado de cuando en cuando como anticipador de Port Royal o como el último heredero de una larguísima tradición con orígenes bastante diversificados y problemáticos. Del Brocense será examinada en las páginas que siguen únicamente la teoría de la elipsis (32), se estudiarán en particular algunas interpretaciones modernas hechas sobre él y se propondrán luego algunas consideraciones personales. No creo necesaria la justificación de la elección de esta parte de la teoría sanctiana; no obstante, las siguientes palabras de Luis Michelena aclaran perfectamente el interés excepcional que desde los contemporáneos del Brocense hasta nuestros dias ha revestido la problemática concerniente a la elipsis:

En la doctrina de la elipsis se ha visto siempre, unas veces con admiración y otras con desdén, el núcleo del pensamiento lingüístico del Brocense $-y$ refiriéndose a la obra de Constantino García - . Por ello, decir que a las anomalias o figuras de construcción in genere dedica éste el cuarto libro de la Minerva, da una idea inexacta de la misma distribución material de ese libro en que la elipsis se lleva claramente, aun en número de páginas, la parte del león. (Michelena, 1975, págs. 434-435).

En efecto, el libro entero está de algún modo tocado por la teoría de la elipsis, que es central no sólo en sentido cuantitativo, sino sobre todo en cuanto sintesis, ejemplo emblemático, de toda la argumentación sanctiana (cfr. Sánchez Barrado, 1919b).

Naturalmente, las interpretaciones recientes de la elipsis que contienen un cierto interés han nacido a continuación de la cita del Brocense hecha por Chomsky en Lingüistica cartesiana y sobre todo en El lenguaje y el entendimiento. Chomsky se ocupa de Sánchez de las Brozas únicamente como precursor de Port Royal e incluso el concepto de elipsis es visto desde esa perspectiva; asi, el Brocense chomskyano (33) ni siquiera es capaz de explicar plenamente el papel jugado por la elipsis en la teoría gramatical:

(32) Sobre la historia de la elipsis, cfr. Giuliani-Puglielli, 1975. Reservo para ulteriores trabajos la profundización de otras temáticas, como por ejemplo la relativa al problema de la alternativa entre empirismo y racionalismo.

(33) De aquel Sánchez de las Brozas al que Lancelot tributaba un largo y significativo elogio en el prefacio a la tercera edición de Nouvelle méthode pour apprendre facilement et en peu de temps la langue latine. 
No hay duda de que en su exposición del concepto de la elipsis como una propiedad fundamental del lenguaje, Sánchez dio muchos ejemplos lingüísticos que exteriormente guardan un estrecho paralelo con los que se usaron para desarrollar la teoría de la estructura profunda y superficial, tanto en la gramática filosófica clásica como en sus variantes modernas, que sin duda son más explícitas. Parece, sin embargo, que, en la intención de Sánchez, la elipsis tiene meramente la función de un instrumento para la interpretación de los textos. (Chomsky, 1980, pág. 30).

Refiriéndose a Huarte de San Juan (34), Chomsky sostiene que con Port Royal se intenta elaborar el segundo tipo de ingenio huartiano tratando de determinar cuáles son las características de la «inteligencia normal» (estamos, pues, en el ámbito psicológico); la elipsis de Sánchez de las Brozas, en cambio, es para Chomsky una simple técnica para interpretaciones textuales, útil como técnica, pero que no nos dice mucho acerca de la organización mental del hombre. Ciertamente, no era difícil descubrir que esta tesis era debida a una lectura superficial de la Minerva (por otra parte, no se puede pretender que Chomsky posea una erudición enciclopédica); bastaba a este propósito leer las primeras páginas de dicha obra para ver que el Brocense era un teórico verdadero y original. De esto se dio cuenta en 1969 Robin Lakoff (35), quien ha visto en las propuestas sanctianas algo mucho más importante de cuanto ha creído Chomsky: «his work [del Brocense] is interesting not only for its specific linguistic analyses, which will be discussed below, but more particularly for his general views of language as it is related to psychology» (R. Lakoff, 1969, pág. 357). Este papel fundamental del Brocense se demuestra en particular desde el primer capítulo de la Minerva, donde, según Lakoff, se exponen cuatro temas principales: 1) el lenguaje como producto de la mente humana y, siendo ésta racional, el lenguaje como «cosa» racional; 2) necesidad de explicaciones de los fenómenos gramaticales; 3) ausencia de accidentalidad en el lenguaje, y 4) irrelevancia de la autoridad en las consideraciones gramaticales. Para Robin Lakoff estos puntos son idénticos a los que elaboró la gramática de Port Royal; podriamos hablar, pues, de «lingüistica sanctiana» con mayor propiedad de la que tendríamos usando la etiqueta de «lingüistica carte-

(34) Huarte, 1977. Por otra parte profundamente malinterpretado, cfr. Arduini (en prensa).

(35) Cfr. Lakoff, 1969. Que esta recensión es hoy día totalmente actual lo demuestra su reimpresión idéntica - sólo faltan las primeras cuatro líneas - como artículo en el volumen misceláneo preparado por Parret, 1976. 
siana». Este cuadro no ha sido comprendido por Chomsky, que ha hecho de Francisco Sánchez un lingüista aplicado y no un teórico;

But since the Minerva is inaccessible to anyone who does not read Latin, Chomsky has been forced to rely on the judgments of writers like Sahlin (1928), some of whose comments on Sanctius demonstrate an amazing lack of perception, much like her lack of perception that Chomsky derides with reference to the GGR. But no one who takes the trouble to read Sanctius carefully could think of him as primarily a textual critic. IR. Lakoff, 1969, págs. 359-360).

Al considerar a Sánchez de las Brozas, Chomsky se deja desviar por las continuas citas de los clásicos, que pueden dar la sensación de un interés textual, no teórico, del gramático español; pero no es así; según Robin Lakoff, el primer capítulo, en particular, nos muestra cómo el interés del Brocense era sobre todo teórico, cómo era su intención determinar las causas (las explicaciones, para Lakoff) de la lengua latina. Es el mismo espíritu con que trabaja la gramática general y es un motivo más para afirmar la procedencia sanctiana de las consideraciones de Arnauld y Lancelot sobre la naturaleza del lenguaje. Robin Lakoff llega todavía más adelante en la valoración de la obra del Brocense al realzar no sólo un estrecho parentesco con la gramática general (con ventaja absoluta para el primero), sino también al sostener una verdadera naturaleza transformacional de la gramática sanctiana. La consideración de una base lógica para todas las lenguas es un claro indicio de este estrecho parentesco; tal base es, por otra parte, subrayada por dos conceptos fundamentales en Sánchez de las Brozas:

One concept is the necessity of recoverability of deletion: one needs to be able to tell from the surface structure what was present in the deep structure. Second is the concept we have discussed at length above of the division between an underlying abstract structure (simple syntax) and superficial structure (figurative syntax). R. Lakoff, 1969, pág. 361).

Sobre la misma línea de Lakoff - subrayando por tanto la derivación de la gramática general a partir de la gramática sanctiana y el propósito de hacer hincapié concretamente en las estructuras lógicas dentro de su teoría del lenguaje - encontramos a Manuel Breva Claramonte con una serie de artículos y trabajos (que tienen su cumbre en la edición anastática de la Minerva) muy útiles para nuestros fines. Las estructuras lógi- 
cas que el Brocense intenta fijar en su gramática son para Breva Claramonte una integración de los niveles histórico y lógico, prueba de ello es toda la teoría de la elipsis, en la que son necesarias tanto la razón como la "venerable antigüedad" para establecer las reglas de la gramática. Cinco son los criterios con los cuales son definidas las estructuras lógicas; "1) 'naturalidad', 2) semántica, 3) comparación de lenguas, 4) filosofía y 5) gramática» (Breva Claramonte, 1980b, pág. 354), además «en su teoría las estructuras lógicas sirven para simplificar la descripción y regularizar determinados fenómenos» (ibidem, pág. 355). Se considera a este propósito como ejemplo el modo en que el Brocense trata el relativo. Éste es colocado, siguiendo a dicho gramático, entre dos casos de un nombre, como en la oración «vidi hominem qui homo disputabat»; la estructura, por lo tanto, sería la siguiente: $\ldots C_{1}+$ relativo + $\mathrm{C}_{2}$; dicha estructura es de gran utilidad en cuanto nos permite un elevado grado de generalización, pues somos capaces de obtener de aquélla todas las derivaciones posibles: «a veces falta el primer caso del nombre (antecedente), 2) a veces está implícito el segundo caso del nombre (consecuente), 3) a veces se hallan suprimidos los dos casos del nombre» (ibidem, pág. 355). Breva Claramonte también propone otro ejemplo (tomado del libro II, capítulo 9) bastante ilustrativo con respecto al modo sanctiano de resolver los problemas. La oración (procedente de las Sagradas Escrituras) sometida a examen es la siguiente: "Lunam et stellas, quae tu fundasti». La estructura lógica subyacente debería ser la siguiente:

...Lunam et stellas, quae negotia tu fundasti

F(rase)

negotia

$$
\mathrm{C}_{1}+\text { relativo }+\mathrm{C}_{2}
$$

o bien negotia $\left(\mathrm{C}_{2}\right)$, que no aparece pero que la "grammmaticae ratio» hace necesaria, explica la oración anterior y el motivo profundo de aquel "quae» neutro justificado por los gramáticos (anteriores al Brocense y contemporáneos del mismo) como absorción de los femeninos «Lunam et stellas".

El último autor que conviene considerar brevemente es Keith Percival, el cual en un trabajo con el indicativo título de «Deep and Surface Structure Concepts in Renaissance and Medieval Syntactic Theory" (cfr. Percival, 1976) asume una posición aún más marcada que la de Robin Lakoff a propósito de la proximidad entre el Brocense y la gramática generativa, posición que de cualquier modo está en la misma línea de 
las anteriormente analizadas. Baste aquí citar el siguiente fragmento sintetizador de todo el modo de tratar la gramática renacentista (además de Sánchez de las Brozas, también Valla, Scalígero, Linacre, etc.):

\begin{abstract}
Parallels between Sanctius' grammatical Theory and transformational grammar are clear and have been discussed by Robin Lakoff; I shall therefore not pursue the point further. On one issue I find myself in disagreement with Dr. Lakoff. Sanctius did not, it seems to me, view ellipsis as a species of interpretation rule only, as she appears to imply. The two notions 'ellipsis' and 'restoration' are complementary: a set of ellipses converts an underlyng non-figurative construction, and restoration does exactly the opposite. Sanctius' concept of ellipsis is therefore closer to the modern notion of transformation than Dr. Lakoff would have us believe (el cursivo es mío). (Percival, 1976, pág. 243).
\end{abstract}

Naturalmente no es posible hacer menos que considerar bastante útiles e iluminantes los análisis realizados por los estudiosos que acabamos de ver, pero, por lo que a mi respecta, alimento algunas dudas de fondo que quiero exponer de modo breve aquí. En primer lugar, una observación metodológica: me parece que los autores citados modernizan demasiado unas concepciones que no son modernas (36), juegan, en definitiva, con excesiva facilidad a una historiografía de la anticipación no siempre válida. Hay que saber distinguir nítidamente en la historia del pensamiento (y por tanto también en la historia de una ciencia), a fin de evitar demasiadas confusiones, dos planos fundamentales: 1) el planteamiento de los problemas y 2) la resolución de los problemas planteados. Desde hace milenios los hombres se plantean las mismas

(36) Breva Claramonte reconoce en parte este hecho en una nota de uno de sus artículos, pero todo lo reduce a una cuestión terminológica (Breva Claramonte, 1980a, pág. 45): (l could be accused of avant-guardism for employing expression such as 'logical', 'deep', 'underlying structure' as well as 'surface' and 'superficial structure'. More traditional terms would be 'simple' and 'figurative' construction or 'natural' and 'artificial' syntax or 'logical' and 'illogical' language. However, the former set of expression has been frequently used in recent literature discussing the work of Sanctius and others...». Donde, en mi opinión, no es totalmente verdadero que "simple» y "figurative» correspondan a "surface" y "superficial structure", respectivamente. Los términos no son meras etiquetas, sino que implican una complicación más profunda (que con frecuencia coincide con el universo entero de una ciencia), y donde la apelación a Chomsky y a otros para legitimar la operación es, en cambio, reveladora del mismo error chosmkyano, que consiste en aproximar puntos particulares de teorias muy lejanas entre si en el tiempo (cfr. Arduini (en prensa)). 
preguntas; en los campos más variados las interrogaciones de base, las preguntas fundamentales, no cambian y vuelven a plantearse a cada generación de estudiosos. Son éstos los problemas filosóficos que angustian a las diversas ciencias teóricas y que parecen inadheribles a cualquier explicación o teoría. No sucede lo mismo, naturalmente, para las respuestas que los hombres dan a aquellas cuestiones siempre idénticas (37). El hombre, el hombre histórico, resuelve en cada época de modo diverso los problemas planteados (así como con frecuencia una misma época da más respuestas a la misma pregunta) según un esquema que podría ser perfectamente el adelantado por uno de tantos historicismos. Es probable, de todas formas, que algunas respuestas, aun lejanas, puedan parecerse, que tengan algunas consonancias, algunos puntos en común, pero no serán nunca las mismas, condicionadas como están por los más diversos accidentes históricos, y siendo en el fondo diversas no podrán ni siquiera ser conmensurables, superponibles recíprocamente; los sistemas teóricos históricamente determinados escapan por consiguiente a una confrontación y el acercar teorías lejanas entre sí - como, por ejemplo, la teoría aristotélica del ímpetu y la mecánica newtoniana - es más bien fuente de error seguro. Por todos estos motivos considero que hay que acoger críticamente y con grandes reservas la exposición de Keith Percival o la de Robin Lakoff, quien, a fin de cuentas, no hace otra cosa que adelantar el comienzo de la gramática generativa desde Port Royal al Brocense o quizá todavía antes (38). Lo mismo puede decirse a propósito de Breva Claramonte y de su intento de ligar nociones como la de estructura profunda y estructura superficial a una teoría gramatical del siglo XVI (con todo cuanto de problemático conlleva tal período) (39). A mi juicio, la cuestión de la elipsis, asi

(37) Respuestas que crean otras preguntas y por consiguiente nuevas respuestas, es decir, todo el aparato de afirmaciones teóricas que posee una ciencia normal. La crisis puede sobrevenir en este punto por dos motivos: 1) porque en la secuencia "pregunta-respuesta-pregunta...» una pregunta o una respuesta producen reflexiones sobre las preguntas o respuestas anteriores, o bien 2) porque la pregunta inicial de base es propuesta de nuevo (tal vez con una formulación diferente) para dirigir la investigación en un sentido completamente diverso del representado por la vieja secuencia "pregunta-respuesta». Lo cual significa que durante el estado «normal» de una ciencia ésta pierde el interés por las preguntas básicas - se limita a resolver los rompecabezas particulares - mientras que en el momento de crisis todo vuelve a ser puesto en juego, con un movimiento que puede proceder de arriba (invalidando la respuesta primitiva) o de abajo (porque se traba el mecanismo pregunta-respuesta).

(38) "Where does transformational grammar really begin?" se pregunta en efecto Robin Lakoff al final de la recensión sugiriendo que se pueda retrodatar incluso antes del Brocense.

(39) Críticas análogas deberán ser hechas a Chomsky, Chevalier, Salmon, Padley, etc. 
como toda la gramática sanctiana (y se podría decir renacentista), está conectada con problemas muy particulares e históricamente fechados, difícilmente separables. Al describir sucintamente las propuestas elaboradas por determinados autores de la época se han visto algunas cosas; otros puntos que interesan son las relaciones con las gramáticas medievales, la disputa entre platonismo y aristotelismo, la cuestión de la pedagogía renacentista, todo el difícil tema de la influencia de Erasmo en Europa. Creo que solamente considerando la gramática renacentista por lo que es, sin dar saltos de siglos o juntando lo injuntable, puede aquélla todavía comunicarnos algo, naturalmente no en las soluciones particulares, sino para aquella historia de las ideas lingüisticas que tanto puede ofrecer en cuanto a la definición de nuestra disciplina.

\section{LA ELIPSIS.}

\subsection{Escribe Keith Percival (40):}

Briefly, Sanctius took his theory of ellipsis from Thomas Linacre's 'De emendata Structura Latini Sermonis' (1524) and his basic metaphysical and syntactic notions from Julius Caesar Scaliger's 'De Causis Linguae Latinae' (1540). (Percival, 1976, pág. 243).

Habria que añadir en dicho cuadro a P. Ramus, cuyo trabajo de formalización de las lenguas francesa, latina y griega tiene una cierta influencia sobre el Brocense, quien sin embargo transfiere a un nivel más abstracto la disposición general. Por lo que se refiere en particular a la elipsis, Keith Percival da un cuadro muy preciso de las influencias, que son múltiples:

The same theory with the same terminology had been stated in the 'De Emendata Structura' of Thomas Linacre sixty years earlier, and we know that Sanctius was familiar with Linacre's work. Moreover, subaudition, the notion basic to the theory of ellipsis, had been a familiar concept in grammatical analysis at least since the Alexandrian period. Lorenzo Valla already provides

(40) Que he criticado por el intento de aproximar la gramática generativa y la teoría del Brocense, pero que es de gran interés en punto a los antecedentes de este último. 
full fledged Sanctian analysis of understood elements. (ibidem, pág. 248) (41).

Pero ¿qué es exactamente la elipsis según el Brocense? La definición más precisa y argumentada a este propósito la encontramos en el libro IV de la Minerva, cuyo título es "De figuris constructionis"; he aquí las palabras del Brocense:

Ellipsis est defectus dictionis, vel dictionum ad legitiman constructionem, ut Paucis te volo; Noctuas Athenas. Terent. Ego ne illam? quae illum? quae me? quae non? Ubi Donatus; Ellipsis est, et Aposiopesis; quasi dicat, si ad Grammaticam spectes Ellipsis est vocum; si vero ad Rhetoricam, Aposiopesis, id est, reticentia, et abruptio sermonis. (Minerva, libro IV, 2).

La elipsis es, por tanto, ausencia de algo, de una o de varias palabras; cometido del gramático es propiamente el de suplir tal ausencia, en otras palabras llenar los vacíos presentes en la oración. Aquí es ya evidente la diferencia con Valla; éste debe resolver sobre todo problemas estilísticos y la elipsis es un artificio que permite la brevedad, una mayor concisión en la expresión de los conceptos (42); en cambio, el Brocense tiene muy cercanos los problemas gramaticales (como él mismo recuerda citando a Fabio: "aliud est Latine, aliud Grammatice loqui»), la elipsis es útil para aclarar mejor la oración e incluirla dentro del esquema «racional» que explica la lengua. Simplificando podríamos decir que Valla "enseña» a elidir y Sánchez de las Brozas a suplir. En esta oposición - estilística vs. gramática - está también la fuerza argumentativa sanctiana contra aquellos que se oponen al uso de la elipsis en los análisis de las oraciones; estos "expertos de la lengua latina" sostienen en efecto:

nihil esse supplendum: nam si supplendum est; Ego amo Dei, et Ego amo Deus, erunt Latinae phrases; quia illic deest, praeceptum; hic autem, quae praecepit» (Minerva, libro IV, 3).

(41) Igualmente con relación a\%la elipsis, Keith Percival propone el cotejo de los pasajes siguientes:

"Ellipsis est deffectus dictionis vel dictionum ad legitimam constructionem»; Sánchez de las Brozas.

«Est enim eclipsis dictionis ad legitimam constructionem necessariae in sensu defectus....); Linacre.

(42) Lo cual, por lo demás, es verdadero también para el Brocense, cfr. Libro IV, 1. 
Carecen éstos, sin embargo, de sentido común, y aquí encontramos uno de los fragmentos fundamentales para la interpretación de la elipsis como algo complejo, profundamente conectado con una filosofía general del hombre y de la historia:

Ego illa tantum supplenda praecipio, quae veneranda illa supplevit antiquitas, aut ea fine quibus Grammaticae ratio constare non potest. (Minerva, ibidem).

Este doble valor histórico y racional (prefiero este término, que es el usado por el Brocense, al término «lógico») ha sido advertido por muchos intérpretes sanctianos; últimamente Breva Claramonte ha realzado su importancia intentando insertarlo dentro de su interpretación generativa de la Minerva. Pero el camino a recorrer es, a mi juicio, diverso; Breva Claramonte llama «deep structure» a esta integración de un nivel histórico y racional; no vamos a repetir aquí en qué consiste la "estructura profunda» (43) chomskyana, tratemos en cambio de analizar la última cita del Brocense ("Ego illa tantum supplenda praecipio...) ) y de ver cuál es su verdadero significado. Los dos términos que hay que examinar son, naturalmente, "antiquitas" y uratio»; captar el valor de ambos significa estar en el buen camino para la realización de un correcto trabajo interpretativo de la elipsis. Advertimos en primer lugar que la «antiquitas» debe ser rigurosamente sometida a la «ratio»:

Haec tam multa invitus cogessi, contra morosos quondam, qui quum in Grammatica rationem explodant, testimonia tantum doctorum efflagitant. An non legerunt Quinctilianum, qui sermonem constare ratione, vetustate, auctoritate, consuetudine scripsit? Ille igitur non rationem excludit, sed in praecipuis enumerat... Usus porro fine ratione non movetur, alioqui abusus, non usus dicendus erit... Reliquum est igitur ut omnium rerum ratio primum adhibeatur; tum deinde si fierit poterit, accedam testimonia, ut res ex optima fiat illustrior. (Minerva, libro I, 1).

La «ratio», por consiguiente, es sin duda un punto de partida; la antigüedad, la autoridad y el uso son una confirmación de lo que la razón ya ha demostrado (Abad, 1982). Intentamos ahora captar rápidamente (y me doy cuenta de ello, insuficientemente) el contexto cultural en el que

(43) Si bien en la actualidad la expresión «estructura profunda» ha sido abandonada en favor de la más precisa «indicador sintagmático». Cfr. los trabajos de Chosmky a partir de Reflexiones sobre el lenguaje; cfr. Scalise, 1981, pág. XLI (nota 25). 
el concepto de «ration (44) habia calado, es decir, tratamos de hallar qué podía entender un hombre del siglo XVI (como el Brocense) cuando utilizaba este término tan controvertido. A fin de despejar en seguida de similitudes ambiguas el campo, diremos que indudablemente el contexto cultural humanístico-renacentista no es el que sirve de fondo al moderno racionalismo (45). Platón y Aristóteles son los dos goznes en torno a los cuales gira la especulación renacentista (y ambos filósofos serán importantes puntos de referencia en la Minerval; un Platón que, tras el parcial desinterés de la Edad Media, es de nuevo estudiado con profundidad, y un Aristóteles que, después de haber sido hondamente criticado (de Valla a Ramus), se intenta reconstruir y releer filológicamente; sobre todo, un Platón y un Aristóteles que, una vez superadas las contraposiciones del primer Humanismo, encuentran a continuación (recordemos, por ejemplo, a Pico della Mirandola y a Pomponazzi) una cierta posibilidad de acuerdo y terminan por confluir, con sus tradiciones, dentro del mismo universo filosófico (46). Los problemas que el aristotelismo y el platonismo del siglo XVI intentarán resolver afrontando disputas cada cierto tiempo, son múltiples y complejos, y están tan enlazados entre sí que necesitan una exposición aparte; tal empresa, obviamente, es aquí imposible, pero pienso que puede ser de interés intentar hacer una simple relación de las problemáticas que hay en juego; se verá así cómo, al ser éste el contexto en el que era usado el término "ratio", cualquier llamada de los modernos es cuando menos improbable.

En primer lugar hallamos cuestiones de orden teológico (libre albedrío, fe y razón, problema del alma, etc.); para ilustrar cómo justa-

(44) Impracticable - sería necesaria una investigación aparte - es intentar aqui una reconstrucción exacta del concepto de uratio" en el siglo XVI; no obstante, creo que las pocas y parciales indicaciones aqui ofrecidas pueden ser suficientes para los fines que nos interesan.

(45) Vasoli, 1968, escribe modélicamente: "Termini come 'empirismo' o 'razionalismo', 'induzione' o 'deduzione' cosi spesso sprecati nonostante tutte le buone intenzioni, hanno ormai un significato storico ben preciso che esula dai temi e dagli argomenti cari ai dialettici umanisti. Sicché appare perfettamente inutile discettare, come è stato fatto con molta serietà, intorno alle origini di questi atteggiamenti di pensiero, individuate magari in certe pagine di Melantone o di Ramon; exposición que sirve naturalmente no sólo para los dialécticos, sino también para los gramáticos (pág. 638).

(46) "Questa ondata di ispirazione platonica che traversa tutto il ' 500 , pervadendo il dominio delle lettere e seducendo i poeti non meno dei filosofi, era ben lungi da ogni intolleranza antiaristotelica. L'Aristotele della Nicomachea, che celebrava ultima perfezione dello uomo il puro contemplare, si accordava perfettamente con la contemplazione platonica" (Garin, 1975, págs. 148-149). 
mente el concepto de razón podía ser puesto en correlación con este orden de problemas, considérese el siguiente paso del «platónico» Ficino:

Il furore divino è una certa illustrazione della Anima razionale, per la quale, Dio, l'anima de le cose superiori a le inferiori caduta, senza dubbio de le inferiori a le superiori ritira. La caduta della Anima da un principio dell'universo infino $a$ ' corpi, passa per quattro gradi, per la mente, ragione, oppenione e natura. Imperocché essendo nell'ordine delle cose sei gradi, de' quali il sommo tiene essa unità divina, lo infimo tiene il corpo: ed essendo quattro mezzi i quali narrammo, è necessario qualunque cade da'l primo insino a l'ultimo, per quattro mezzi cadere. (Ficino, 1914, orazione VII, cap. XIII).

Encontramos seguidamente en esta especie de catálogo de los problemas discutidos en el ámbito renacentista (aristotélico-platónico) la disputa sobre la astrología (Pomponazzi, Pico, Ficino) y la nueva concepción de la naturaleza (47); toda la cuestión concerniente a la filosofía del amor y a la metafísica del amor; los estudios morales y la alternativa entre vida activa y contemplativa; asimismo las discusiones en torno al "Trivium». En qué medida todo esto está extremamente concatenado y juega un papel decisivo en los campos más diversos se puede deducir, por ejemplo con respecto a la iconología, de la evolución de los iconos simbólicos desde la Edad Media al Renacimiento según lo que ha escrito Gombrich (Gombrich, 1978).

¿Qué podría ser, pues, la razón para el Brocense? Probablemente, al igual que sucede en la tradición clásica desde la Grecia antigua, también en este caso razón se opone a opinión, siendo la segunda una perezosa confianza del hombre en los sentidos más inmediatos mientras que la primera somete a verificación las verdades recibidas. Siguiendo a los autores modélicos y relacionando o ignorando incluso las contradicciones reales, la razón, como para Platón, permitirá el conocimiento perfecto de la realidad de las ideas después de que, por medio de la ascesis, el hombre se haya liberado del estorbo de los sentidos; como para los neoplatónicos (cuya tradición continuará en la Escolástica y aun des-

(47) A propósito de Pomponazzi y de su modo de explicar las «differenti specie di predizioni e di fenomeni miracolosi» relativas a la astrología y a la magia, escribe $E$. Cassirer: "Questa verità [de los fenómenos] gli sembra garantita dall'esperienza, e quest'ultima il filosofo critico deve semplicemente accoglierla, senza modificarne il contenuto) (Cassirer, 1974, pág. 165\}. 
pués) el intelecto divino declina a razón en el momento en que da forma al mundo, la razón estará, pues, constreñida, a causa de su imperfección, a avanzar lentamente por el difícil camino del proceso discursivo; en fin, como para Aristóteles, el hombre es el único animal dotado de razón, la cual no será otra cosa que la capacidad de recibir las esencias de las cosas (ideas) desde una inteligencia activa, la única capaz de comunicárselas a través de la percepción de los sentidos (48).

Después de haber visto, si bien mediante breves alusiones, que el concepto de uratio» no puede ser identificado «in toto» con aquella razón a la que apelan los lingüistas contemporáneos (más de cuatro siglos no han pasado en balde) volvemos a considerar la elipsis sanctiana concluyendo la parte de peroración en favor de la elipsis con las siguientes palabras del Brocense:

(48) Para cerrar este intento parcial de contextualización del concepto de "ratio», me gustaría - se me excusará el vicio ecléctico y la larga cita - proponer en las palabras de Cesare Ripa la representación iconológica que precisamente de la razón tuvo el siglo XVI fla primera edición de la /conologia de Ripa es de 1599, pero evidentemente recoge la problemática total del sigio XVI):

\section{«RAGIONE.}

Una giovane, armata, con la corona d'oro in capo, et le braccia ignude, et nella destra mano tenga una spada, et con la sinistra un freno, col quale affrena un Leone, sarà cinta d'una candida benda, dipinta tutta con note d'Arithmetica.

Questa virtú è domandata da Theologi forza dell'Anima, per essere la Regina, che da le vere et legitime leggi à tutto l'huomo.

Si dipinge giovane armata, perché è difesa et mantenuta dal vigore della sapienza, si piglia molte volte presso gli Antichi, l'armatura esteriore, come nel significato di Pallade, et in altri propositi.

La corona d'oro, che tiene in testa, mostra, che la ragiorıe è sola bastante à far scoprire gli huomini di valore, et dar loro splendore, fama, prezzo, et chiarezza, ne è cosí singolare l'oro fra metalli, ancorché sia il piú pregiato, che è piú singolare non sia frà le potenze dell' anima nostra questa, che dimandando Ragione, la quale hà la fede sua nella piú nobile parte del corpo, et ove hà l'anima maggior vigore all'operare.

Per le braccia ignude, s'intendono l'opere, le quali quando hanno principio dalla vera ragione, non hanno macchia, ò sospetto alcuno, che fe veli, ò le adombri; talche non si veda immediatamente vera, et perfetta virtú.

La spada è il rigore, che bisogna adoprare alla ragione, per mantenere netto il campo della virtú da vitij predatori de' behi dell' anima; et à questo proposito disse Christo Signor nostro, Non veni pacem mittere in terram sed gladium; perche tutta la sua dottrina, non fú ad altro diretta, che à fare la disunione de vitij già invecchiati nell'anima, dalla virtú, per mezzo della ragione illuminata dalla sua gratia.

II freno in bocca del Leone, ci nota il senso soggiogato, et sottomesso ad essa, il quale per sè stesso, è ferocissimo, et indomito.

Le note di Arithmetica sono poste, perché con queste si fanno le ragioni in detta arte, che provano'le cose reali, come con la ragione, che stà nell'anima, si prova, et si conosce tutto quelio, che appartiene al ben nostro» (Ripa, 1618, II parte, págs. 436-437). 
Multam etiam Grammaticae ratio nos cogit intelligere quae, si apponerentur, latinitas elegantiam disturbarent aut sensum dubium facerent... Alia rursus videmus desiderari, quae sine vitio suppleri nequerunt, et tamen Grammatica necessitas supplebit... Liceat iam nobis per Grammaticos thesauros Ellipseos aperire, sine quibus iniuriam facit Latino sermoni, qui se Latinum audet nominare. (Minerva, libro IV, 3).

3.2. Damos ahora las reglas que Sánchez de las Brozas antepone a la larga casuística de las diversas posibilidades en las que encontramos la elipsis (49).

\section{REGLAS GENERALES}

Nombre: siguiendo a Platón y a Aristóteles, el Brocense afirma que, no siendo posible tener una oración sin nombre y verbo, un nombre solo no tendrá significado y tampoco un verbo. Ejemplos: en currit, flatur, sedetur, faltan cursus, flatio, sessio. Lo mismo sucede para todos aquellos verbos que son llamados impersonales pasivos, para los verbos de naturaleza (pluit, ningit, lucescit), y para miseret, taedet, pudet, piget y poenitet.

Acusativo (nominativo en la voz pasiva): se sobreentiende el acusativo en aquellos verbos que son llamados absolutos (pero son simplemente activos) como curro, ambulo, sedeo, para los que está sobreentendido cursus, ambulatio, sessio. Se omite el acusativo para evitar el pleonasmo, pero será necesario con la presencia del adjetivo; ejemplo: hila-

(49) Está dividida del modo siguiente: elipsis de los nombres y participios (se ofrecen los nombres y los participios sobreentendidos, desde "acinus» a "uxor»); elipsis de los verbos (relación de verbos sobreentendidos); elipsis de las preposiciones («Praepositionum Ellipsis duabus regulis continetur. Prima: Nullus non ablativus a praepositione pendet; Altera: Accusativus, qui nec sit infiniti suppositum, nec activorum appositum, a praepositione pendet»); elipsis de la preposición en nombres de ciudad, provincia e isla; "de ablativo quem falso absolutum vocant»; elipsis de las preposiciones de instrumento; de las del comparativo y de las de precio; elipsis de a o de en los verbos de abundancia y escasez; elipsis de otras preposiciones; elipsis de adverbios y conjunciones. Sigue después, dentro del libro IV, un examen del zeugma, del pleonasmo, de la silepsis, del hipérbaton y de la antiptosis. Cierran el libro los siguientes epigrafes: "De ellipsi praepositionis, katà, id est, iuxta, vel secundum, vel pen); "unius vocis unica est significatio»; "de analogia significationum»; "exploditur grammaticorum antiphrasis»; "responsio ad quaedam obiecta»; "Lectori»; y finalmente el famosísimo "Qui latine garriunt, corrumpunt ipsam latinitatem". 
rem vitam vivis. «Itaque omnia verba sunt activa, aut passiva: nam teste Aristotele, omnis motus aut actio est, aut passio, nihil medio est» (50).

Infinitivo en lugar del nombre: en caso de que falte el nombre verbal recurriremos al infinitivo del mismo verbo para evitar indicar el agente cuando esto es imposible: «nam si Cato vivit, vitam vivit, vel vivere; et placet placere: et vadit vadere; pergit pergere; et caret carere».

El nombre mismo: cuando después del verbo sustantivo hay un adjetivo o un genitivo es necesario sobreentender el mismo nombre; ejemplo: hoc pecus est regium; es decir, hoc pecus est pecus regium. Además:

Ubi genitivus ab adiectivo videtur discrepare, praecipiunt isti [los gramáticos] esse Graecismum aut Antiptosim; ut, multos militum amisit, id est multos milites... Sed non ita est; nunquam enim adiectivum sine substantivo erit; supplendum igitur idem nomen. Livius libr. 9 dec. 4. Neque earum rerum ullam rem, in quas iureiurando obligati erant, in se, aut in alios admiserant.

Ex numero: el nexo «ex numero» se sobreentiende en toda construccion partitiva con verbos o adjetivos posesivos, comparativos, superlativos, numerales o de cualquier modo que aparezca el genitivo: hispanorum alii vigilant alii student, quidam boni, quidam mali, quidam fortiores, alii fortissimi, i.e. ex numero hispanorum. $O$ bien: Censor maxime, principumque princeps, "Unde licebit exibilare Grammatistas, qui pueris inculcant superlativa regere genitivum, et comparativa inter duo...l (51).

Ego, tu, nos, vos: construcción de mayor elegancia es no expresar en la primera y segunda persona el sujeto. Esta llamada casi valliana a la elegancia no resultará extraña solamente si se tiene en cuenta la extrema problematicidad de las teorias gramaticales del siglo XVI; es un motivo más para no hacer del Brocense un lógico férreo o para no modernizarlo demasiado.

(50) De este modo, la elipsis es aclarada mejor gracias a una afirmación general de Aristóteles.

(51) «Ridicula vero sunt quae inculcat Valla de, unus et solus lib. 3. cap. 67. esse scilicet nomina duo ex natura superlativorum, regereque genitivum... Rectius Thom. Linacer lib. 6. Nomen, inquit cum praepositione deest, ut ante tales genitivos. Animalium, fortiora, quibus est sanguis crassior: subauditur enim de numero, vel ex numero». 
Me, te, se: no se expresan me, te, se, cuando la acción recae sobre el sujeto mismo; ejemplo: nox praecipitat; hyema adventat, bene habet.

Nec verum est quod docet Servius et alii Grammatici, esse aliqua verba activa pro passivis posita, ut nox praecipitat, pro praecipitatus; et volventibus annis, pro volutis etc. Immo vero deest se, ut recte docet Linacer.

Del mismo modo deben entenderse pluit, ningit, serenat, tonat; i.e. pluvia pluit se o pluvia pluvit pluviam.

Genitivo: se calla no sólo el nombre (del cual con frecuencia depende un genitivo) sino incluso el genitivo que podría ser expresado:

Qua de re est elegantissimum Ciceronis locus, qui nostram supplendi doctrinam maxime illustrat, in 2 . lib. Natu. Deorum; sed id, inquit, praecise dicitur, ut quis dicat, Atheniensium rempublicam consilio regi, desit illud, Areopagi; sic quum dicimus, providentia mundum administrari.

3.3. Tras haber visto de cerca el método del Brocense al ubordar los problemas relativos a la elipsis reconsideramos ahora, antes de concluir proponiendo ejemplos concretos del uso sanctiano de la elipsis, el análisis adelantado por Breva Claramonte con respecto al tratamiento del relativo en la Minerva. Confrontamos a continuación el fragmento con el que Breva Claramonte abre su exposición sobre el relativo con el fragmento inicial de Sánchez de las Brozas al que aquél se refiere:

Underlying structures simplify the description of Latin, i.e., they reduce the number of rules and show the regularity of certain phenomena which at first sight appear anomalous. This is the regularity of the originally logical language, which in my opinion he was attempting to reconstruct. (Breva Claramonte, 1980a, pág. 51) (52).

Rogabit aliquis, cur in arte Grammatica non proposuerimus pueris aliud esse relativum substantiae, aliud accidentis; rogabo ego illos cur velint artes confundere, et facere ut ne intelligendo nihil intelligant. Haec et alia multa sustuli, quae ad Grammaticum, etiam perfectissimum, nihil attinet: satis est enim grammatico scire, Tantus, quantus; Talis, qualis; Tot, quot esse nomina adiectiva, nullamque habere relationem, nisi dialecticam, ut pater, filius, discipulos, magister. (Minerva, libro II, 9). 
Estos dos comienzos ya muestran, pienso, el abismo conceptual que separa ambas posicior যs; en cualquier caso resulta clara la posición del Brocense, para el c.Jal, como gramático, es suficiente saber que "tantus, quantus» $s$ adjetivos, y así sucesivamente (53). Breva Claramonte sostiene que el Brocense quiere reconstruir el lenguaje lógico originario, pero pare ie ignorar que cuando el gramático extremeño habla de lengua primeia o de lengua originaria entiende la lengua adánica "cualquiera qu'e ésa sea», y dudo, llegado a este punto, que sea posible un acercamiento no sólo a la gramática generativa, sino a cualquier hipótesis moderna.

Con respecto al problema de la interpretación del relativo, hemos visto ariteriormente cómo lee Breva Claramonte la propuesta sanctiana, pero no hemos escuchado la voz del Brocense; hagámoslo ahora:

Diximus itaque, relativum collocari inter duos casus nominis unius, ut vidi hominem, qui homo disputabat. Hunc loquendi modum taxat $D$. Hieronymus in Ruffinum; sed multa sunt testimonia quae nostram regulam confirmant.

$y$ tras ofrecer una larguísima serie de ejemplos:

solet in relativo deesse primus casus, aliquando secundus, nonnunquam ambo simul.

(52) Breva Claramonte coloca en este punto una nota (11) en la que expresa que un pasaje del libro I adquiere significado en este contexto; propone para dicho pasaje la siguiente traducción inglesa: "Undoubtedly the logic of all things and also of words can be reconstructed. If one is asked about this logic, let us say if we do not know, that we do not know rather than asserting continually that there is no logic" (Breva Claramonte, 1980a, pág. 55). El texto original es el siguiente: «Non igitur dubium est, quin rerum omnium, etiam vocum, reddenda sit ratio; quam si ignoraverimus rogari, fateamur potius nos nescire, quam nullam esse constanter affirmare") (libro I, 1). En mi opinión, es arbitrario traducir «ratio» por "logic»; mientras este último término tiene un significado muy moderno, definido de manera precisa, el término sanctiano es bastante más genérico e impreciso y en todo caso se refiere a un concepto de razón diverso del de la lógica actual o de la lingüistica formal.

(53) «La gramática tiene un objeto de estudio preciso, distinto del de la filosofia, historia, etc. (afirmación en la que se detiene durante todo el capitulo segundo del libro primero)... Refiriéndose al mismo tema, en otra ocasión llega a negar que sea ocupación del gramático el estudio de las significaciones. Ello sería propio del filósofon (Riveras Cárdenas, 1976, pág. 19). El estudio de las relaciones lógicas es aceptado en una segunda etapa, pero como algo distinto del estudio gramatical, cfr. además Garcia Salinero, 1973, págs. 441-442. 
Éste es el texto del Brocense; siguiendo a Breva Claramonte podemos sintetizar tal explicación con la fórmula " $\ldots C_{1}+$ relativo $+C_{2} \ldots$ y es también adecuado recordar el buen grado de generalización alcanzado, pero francamente me parece excesivo hablar de estructura profunda o de estructura lógica. El Brocense quiere determinar las "causas» de la lengua latina, las "causas», es decir las «razones» (y sobre este término ya he dicho algo), lo que no quiere decir necesariamente "estructuras lógicas», concepto que, al contrario, debía estar bastante lejano, en su acepción moderna, de la mente de un gramático del siglo XVI (las estructuras lógicas son para el Brocense, a lo sumo, las categorias lógicas en sentido aristotélico). La elipsis es un instrumento óptimo para este fin, puesto que nos explica lo inexplicable o cuanto hasta entonces había sido explicado demasiado intuitivamente y además nos permite obtener un esquema general que evite soluciones "ad hoc»; el «racionalismo» del Brocense está todo aquí: «El hombre está dotado de razón y en todo lo que realiza ha de observar la operancia de ese elemento constitutivo de su propia esencia» (Riveras Cárdenas, 1976, pág. 18). Hallamos aquí, además, el verdadero significado del nombre dado a este libro de gramática: Minerva, Palas Atenea, diosa de la inteligencia, de las artes y de las ciencias, hija de Metis, la mente, y de Zeus que la dio a luz, adulta, de su propia cabeza. Pretendo con esto decir que la elipsis sanctiana es sin duda mucho más que un puro artificio para el análisis textual (como es para Chomsky), pero al mismo tiempo es mucho menos que un medio para obtener estructuras profundas en sentido moderno; es, más simplemente, un instrumento, bastante potente para una gramática del siglo XVI, de «racionalización» de los datos lingüísticos.

3.4. Concluyo proponiendo a título de ejemplo algunos casos de la utilización sanctiana de la elipsis en los nombres, verbos, preposicior ies, adverbios y conjunciones.

\section{ELIPSIS DE NOMBRES Y PARTICIPIOS}

Arbor. "Delphica laurus, tarda morus, patula fagus, subaudi arbor; nam nomen generale rectius subauditur aliquando additur». tica.

Ars, scientia. Falta ars en las palabras: grammatica, rhetorica, dialec-

Foemina. "Boves meas, canes gravidas, cum legimus, ne credamus 
Grammaticis, nomina communia doubus, maxima cum ignorantia sunt commenti, sed subintelligamus foeminas...»

Homo. Falta homo en los adjetivos masculinos puestos en modo absoluto; ejemplos: tu es miser, ego sum salvus, Petrus est albus.

Urbs, oppidum. «Narbo ex terminatione masculinum est, ut Sulmo et Hippo, vel Hippon. Sed barbara Narbo, subaudi, urbs; magna Tarentum, supple, urbs».

\section{ELIPSIS DE VERBOS}

Est. Con frecuencia se sobreentiende el verbo est; ejemplo: Quid graculo cum fidibus, es decir, est. Cuando encontramos la partícula vae, ésta no rige (como creen los gramáticos, escribe el Brocense) el dativo siguiente, sino que es sobreentendido el verbo est; ejemplos: malum tibi; vae tibi; etc.

Coepit. Se dice que el infinitivo tiene valor de imperfecto; ejemplo: populus ea mirari, es decir, mirabatur; mejor sería afirmar que falta coepit.

Verbo incierto. "In Aposiopesi Rhetorum incertum verbum eleganter deest. Terent. Ego ne illam; quae illum? quae me? quae non. Ubi Donatus Ellipsin et Aposiopesin agnoscit... Idem contingit in orationibus animi affecti».

Oro, precor. Ut es a veces considerado como utinam, ejemplo: Ut Syre te cum tua monstratione magnus perdat lupiter (Ter. Adel.); en cambio falta oro o precor o quaeso, ejemplo:.Deos quaeso, ut sit superstes (Ter. And.).

\section{ELIPSIS DE PREPOSICIONES}

Nombres de ciudad, provincia e isla. En estos nombres falta con frecuencia una preposición, como en tendit Romam, Aegiptum, Italiam.

Preposiciones de instrumento. Cuando se quiere expresar un instrumento falta frecuentemente cum, que se sobreentiende para evitar ambigüedad; por ejemplo: en testigi illum cum hasta, «nescitur an illum et hastam testigeris, an vero instrumentum significes». No obstante, el 
cum se expresa cuando no existen dudas de partida. El instrumento se puede expresar igualmente mediante otras preposiciones: $s u b, a b$, in.

Preposición del comparativo. «Deesse praepositionem in ablativo comparativi comprobant omnium linguarum idiomata, Hebreae praecipue, quae nomina comparativa non habet, sed comparationem, per hanc particulam MI enunciat; sicut Graeci per H. Latini per QUAM. Hispani per MAS. Mihi, quantum ex veterum lectione observo in praepositionibus, non in nominibus, videtur esse vis comparationis; nam et in verbis, et positivis, comparativis, et superlativis apparet comparatio, virtute praepositionis... Si igitur in praepositione significatur comparatio, necessario in ablativis comparationis deest prae. Plaut. Epid. Atque me minoris fatum pre illo, ubi per Ellipsin dici poterat minoris illo». Lo mismo en el superlativo $y$ en el positivo.

Verbos de abundancia y escasez. En estos verbos percibimos un efecto de causa eficiente porque falta a o de.

\section{ELIPSIS DE ADVERBIOS Y CONJUNCIONES}

Ne. En frases como cave cadas o cave faxis falta ne, es decir, cave ne cadas, cave ne faxis.

Non. Detrás de non modo, non solum, non tantum, es sobreentendido non; ejemplo: Alexander non modo parcus, sed etiam fuit liberalis, es decir, Alexander non solo non parcus...

Prius. La partícula prius falta con frecuencia delante de quam.

Vel. "Vel particula saepe subiticetur... sed aliud habet etiam elegantioris considerationis; nam quum dicis vel stultus, haec intelligeret: vel Priamo miseranda manus, deest aliud vel, ut sit vel Priamo, vel aliis hostibus. Scio Donatum accipere, vel, pro etiam. Budaeus in commentariis exponit pro nam. Donatus rursus in Phormio pro saltem. Ego vero, cui unius vocis unica semper est significatio, semper disiungentem particulam affero, et alterum, vel, deesse confirmo. Hoc praeclare elicies ex Persio Saty. 1. Nemo Hercule, inquit, leget haec vel duo, vel... Itaque particula, vel, sola poni non potest, nisi aliud vel intelligantur».

(Doy las gracias a Tomás Albaladejo por su amable traducción al español). 


\section{REFERENCIAS}

Aarslef, H. (1970), "The History of Linguistics and Professor Chomsky», Language, 46, págs. 570-585.

-(1971), "Cartesian Linguistics: History or Fantasy?», Language Sciences, 17, págs. $1-12$.

- (1974), "The Tradition of Condillac: the Problem of the Origin of Language in the Eighteenth Century and the Debate in the Berlin Academy before Herdern, en: Hymes (1974), págs. 93-156.

Abad Nebot, F. (1982), Los géneros literarios y otros estudios de Filologia, Madrid, Universidad Nacional de Educación a Distancia.

Abellán, J. L. (1982), El erasmismo español, Madrid, Espasa-Calpe, $2^{\text {a }}$ ed.

Alonso, A. (1949), «Examen de las noticias de Nebrija sobre antigua pronunciación española», Nueva Revista de Filologia Hispánica, 3, págs. 1-82.

Ape!, K. O. (1963), Idea di lingua nella tradizione dell'umanesimo da Dante a Vico, Bolonia, II Mulino.

Arens, H. (1975), La lingüistica. Sus textos y su evolución desde la Antigüedad hasta nuestros dias, Madrid, Gredos, 2 vols.

Arduini, S. (en prensa), "Chomsky e la storia delle idee linguistiche».

Asensio, E. (1960), «La lengua compañera del imperio. Historia de una idea de Nebrija en España y Portugal», Revista de Filología Española, 43, págs. 399-413.

Bahner, W. (1966), La lingülstica española del Siglo de Oro, Madrid, Ciencia Nueva.

Bassols de Climent, M. (1946), «Nebrija en Cataluña», en: Miscelánea Nebrija, págs. 49 64.

Bataillon, M. (1966), Erasmo y España, Méjico, Fondo de Cultura Económica.

Bell, A. F. G. (1925), Francisco Sánchez el Brocense, Oxford, Oxford University Press. - (1944) El Renacimiento español, Zaragoza.

Bonilla y San Martín, A. (1981), Luis Vives y la filosofia del Renacimiento, Madrid, Real Academia de Ciencias Morales y Políticas

Bracken, M. (1972), "Chomsky's Cartesianism», Language Sciences, 22, págs. 11-17.

Breva Claramonte, M. (1977), «Sanctius' Antecedents: The Beginnings of Transformational Grammarn, Language Sciences, 44, págs. 10-18; 45, págs. 6-21.

-(1978a), Recensión de G. A. Padley (1976), Ars Semeiotica: International Journal of American Semiotics, 1-2, págs. 59-80.

$-(1978 \mathrm{~b})$, "The Sign and the Notion of 'General' Grammar in Sanctius and PortRoyal", recensión de J. Rieux y B.E. Rollin, Arnauld et Lancelot; General and Rational Grammar: The Port-Royal Grammar, La Haya, Mouton, 1975.

- (1980a), "Logical Structures in Sanctius' Linguistic Theory», Amsterdam Studies in the Theory and History of Linguistic Science, 3. Studies in the History of Linguistics, vol. 20, K. Koerner (ed.), Progress in Linguistic Historiography, Amsterdam, John Benjamins, págs. 45-57.

-(1980b), "La teoría gramatical del Brocense en los siglos XVII y XVIII», Revista Española de Lingüistica, 10, 2, págs. 351-371.

$-(1980 \mathrm{c})$. Sanctius' Theory of Language: a Contribution to the History of Renaissance Linguistics, Amsterdam, John Bènjamins.

- (1980d), Sanctius' Minerva seu de causis linguae latinae, Grammatica Universalis, 16, 2 vols., reproducción facsimilar, Stuttgart-Bad Cannstat, Frommann.

Cassaci, A. (1926), «Gli Elegantiarum libri di L. Valla», Atene e Roma, 7, págs. 187-207.

Casares, J. (1947), «Nebrija y la gramática castellana», Boletín de la Real Academia Española, 26, págs. 335-367.

Cassirer, E. (1974), Individuo e cosmo nella filosofia del Rinascimento, Florencia, La Nouva Italia.r 
Chevalier, J.C. (1968), Histoire de la syntaxe: naissance de la notion de complément dans la grammaire française (1530-1750), Ginebra, Droz.

Chomsky, N. A. (1977), El lenguaje y el entendimiento, Barcelona, Seix Barral.

-(1979), Reflexiones sobre el lenguaje, Barcelona, Ariel.

Coseriu, E. (1977), "Acerca de la teoría del lenguaje de Juan Luis Vives», en E. Coseriu,

Tradición y novedad en la ciencia del lenguaje, Madrid, Gredos, 1977, págs. 62-85.

Delbrück, B. (1893), Grundriss der vergleichende Grammatik der indogermanischen Sprachen, Estrasburgo.

Dorstet, L. (1972), "Descartes on Language», en M. Esteille Smith (ed.), Studies in Linguistics in Honor of George L. Trager, La Haya-Paris, Mouton.

Fernández-Sevilla, J. (1974), "Un maestro preterido: Elio Antonio de Nebrija», Thesaurus, 29, págs. 1-33.

Ficino, M. (1914), Sopra lo Amore ovvero Convito di Platone, edición cuidada por G. Rensi, Lanciano.

Fois, M. (1969), "ll pensiero cristiano di L. Valla nel quadro storico del suo ambiente», Analecta Gregoriana, 174.

Gaeta, F. (1955), Lorenzo Valla. Filologia e storia nell'umanesimo italiano, Nápoles.

Galindo Romeo, P. y Ortiz Muñoz, L. (1946), «Introducción» a A. de Nebrija, Gramática de la lengua castellana, Madrid, Consejo Superior de Investigaciones Científicas, 1946.

García, C. (1961), Contribución a la historia de los conceptos gramaticales. La aportacion del Brocense, Madrid, Consejo Superior de Investigaciones Científicas.

García Berrio, A. (1977-1980), Formación de la Teoría Literaria moderna, vol. I, Madrid, Cupsa; vol. II, Murcia, Universidad de Murcia.

García Salinero, F. (1973), «Actualidad lingüistica de Francisco Sánchez de las Brozas», Revista de Estudios Extremeños, 29, págs. 431-443.

Garin, E. (1975), L'umanesimo italiano, Bari, Laterza, 6 ed.

Geanakoplos, D. J. (1967), Bisanzio e il Rinascimento, Roma, Ateneo.

Gili Gaya, S. (1947), «Nebrija et sa grammaire castillane», Les Langues Néo-Latines, 42, n. 105.

Giuliani, M. V. y Puglielli, A. (1975), «Aspetti teorici dell'ellissi nella tradizione grammaticale», en Società di Linguistica Italiana, Teoria e storia degli studi linguistici (Atti del VII Convegno Internazionale di Studi, Roma, 1973), Roma, Bulzoni.

Gombrich, E. H. (1978), Immagini simboliche, Turín, Einaudi.

González Llubera, 1. (1926), «Introducción» a A. de Nebrija, Gramática de la lengua castellana, Londres, Oxford University Press.

Guy, A. (1973), Vives ou l'Humanisme engagé, Paris, Seghers.

Hall, V. (1950), "Life of Julius Caesar Scaliger (1485-1558)», Transaction.

Hornedo, R. M. de (1943), "Los estudios de gramática en la Universidad de Salamanca desde 1583 a 1588", en Miscelánea Comillense, l, págs. 589-638.

Huarte de San Juan, J. (1977), Examen de ingenios para las ciencias, edición cuidada por E. Torre, Madrid, Editora Nacional.

Hymes, D. (ed.) (1974), Studies in the History of Linguistics: Tradition and Paradigms, Indiana University Studies in the History and Theory of Linguistics, Bloomington, Indiana University Press.

Kukenheim, L. (1932), Contributions à /'histoire de la grammaire italienne, espagnole et française à l'époque de la Renaissance, Amsterdam.

- (1951), Contributions à l'histoire de la grammaire grecque, latine et hébraïque de la Renaissance, Leiden, Brill.

Joly, A. y Stéfanini, J. (1977), La grammaire générale. Des modistes aux idéologues, Lille, Publications de l'Université de Lille III, Presses Universitaires de Lille.

Lakoff, R. (1969), Recensión de C. Lancelot y A. Arnauld, Grammaire générale et raisonnée, ou la grammaire de Port-Royal, edición cuidada por H.H. Brekle, 2 volș., 
Stuttgart-Bad Cannstat, Frommann, Language, 2, págs. 343-364.

Lancelot, C. y Arnauld, A. (1969), Grammatica e logica di Port-Royal, al cuidado de R.

Simone, Roma, Astrolabio.

Lapesa, R. (1981), Historia de la lengua española, Madrid, Gredos, $9^{a}$ ed. corregida y aumentada.

Lázaro Carreter, F. (1949), Las ideas lingüísticas en España durante el siglo XVIII, Madrid, Consejo Superior de Investigaciones Cientificas.

Liaño Pacheco, J. M. (1971), Sanctius el Brocense, Madrid, Universidad de Salamanca.

Linacre, T. (1544 (1524)), De emendata structura Latini sermonis libri sex, Lyon.

- (1546), Rudimenta Grammatices, Lyon.

Manzoni, B. (1960), Vives. Umanista spagnuolo, Lugano, Cenobio.

Marsh, D. (1979), "Grammar Methods and Polemics in L. Valla's Elegantiae», Rinascimento, II, 9, págs. 91-116.

Menéndez Pelayo, M. (1974), Historia de las ideas estéticas en España, Madrid, Consejo Superior de Investigaciones Cientificas, 2 vols.

Merril, J. S. (1970), «Las primeras clasificaciones tripartitas de las partes de la oración: Villalón y el Brocense», Nueva Revista de Filología Hispánica, 19, págs. 105-119.

Michelena, L. (1975), "El Brocense hoy», en: Homenaje a la memoria de D. Antonio Rodriguez Moñino, 1910-1970, Madrid, Castalia, págs. 429-442.

Miel, J. (1969), "Pascal, Port-Royal, and Cartesian Linguistics", Journal of the History of ldeas, 30 , págs. 261-271.

Miscelánea Nebrija (1946), Madrid, Consejo Superior de Investigaciones Científicas.

Morante, M. de (1859), «Biografía del maestro Francisco Sánchez de las Brozas» (en el volumen $\vee$ del Catalogus librorum doctoris $D$. Joach. Gómez de la Cortina, Madrid).

Moreau, J. (1967), "Sánchez précartesien», Revue Philisophique de France et de l'étranger, 92, págs. 264-270.

Navarro Funes, A. (1929), "La teoría de las formas gramaticales según el Brocense»,

Boletín de la Universidad de Granada, 1, 5-6, págs., 3-55.

Nebrija, A. de (1523), Introductiones in Latinam grammaticam, Alcalá de Henares.

- (1981), Gramática de la lengua castellana, edición cuidada por A. Quilis, Madrid, Editora Nacional.

Olmedo, F. G. (1942), Nebrija (1441-1522), Madrid, Editora Nacional.

Ortega y Gasset, J. (1973), Vives-Goethe, Madrid, Revista de Occidente.

Oteı, C.P. (1973a), "Lancelot 'avant la lettre': Sánchez de las Brozas", en C. P. Otero, Introducción a la lingüistica transformacional (Retrospectiva de una confluencia), Méjico, Siglo XXI, págs. 32-39.

- (1973b), "La Minerva en Port-Royal», en C. P. Otero, Introducción..., págs. 45-50.

Padley, G. A. (1976), Grammatical Theory in Western Europe 1500-1700: the Latin Tradition, Cambridge, Cambridge University Press.

Pagliaro, A. (1930), Sommario di linguistica arioeuropea, I, Cenni storici e questioni teoriche, Roma.

Parret, H. (ed.) (1976), History of Linguistic Thought and Contemporary Linguistics, Berlín-Nueva York, De Gruyter.

Percival, W. K. (1976), "Deep and Surface Structure Concepts in Renaissance and Medieval Syntactic Theory», en Parret (ed.) (1976), págs. 238-253.

Prandi, A. (1971), Interpretazioni del Rinascimento, Bolonia, II Mulino.

Quilis, A. (1981), "Estudio», introducción a A. de Nebrija, Gramática de la lengua castellana, Madrid, Editora Nacional, 1981.

Ramus, P. (Pierre de la Ramée) (1559), Scholae grammaticae, Frankfurt.

-(1562), Gramere, París.

Rico, F. (1978), Nebrija frente a los bárbaros, Salamanca, Universidad de Salamanca. 
Ripa, C. (1618), Iconologia, Pauda, P. Tozzi.

Robins, R. H. (1974), Breve historia de la lingüistica, Madrid, Paraninfo.

Rosiello, L. (1967), Linguistica illuminista, Bolonia, II Mulino.

-(1979a), "Le teorie linguistiche e grammaticali dell'enciclopedismo illuminista», / Pensiero Politico, 12, 2, págs. 263-284.

-(1979b), Artículo "Lingua» en la Enciclopedia Einaudi, VIII (L-M), Turín, Einaudi, págs. 287-340.

Sabbadini, R. (1922), // metodo degli umanisti, Turin.

Saitta, G. (1961-1962), // pensiero italiano nell'Umanesimo e nel Rinascimento, Florencia.

Sánchez Barrado, M. (1919a), "Estudios sobre el Brocense», Revista Crítica HispanoAmericana, 5, 1, págs. 1-26.

- (1919b), La elipsis según el Brocense en relación con su sistema gramatical, Segovia. Sánchez de las Brozas, F. (1587), Minerva seu de causis linguae Latinae, Salamanca, Renaut.

- (1766), Opera omnia, edición cuidada por G. Mayáns y Siscar, Ginebra.

- (1975), Minerva seu de causis linguae Latinae, edición cuidada por E. del Estal Fuentes, Salamanca, Universidad de Salamanca.

- (1976), Minerva o de la propiedad de la lengua latina, introducción y traducción de F. Riveras Cárdenas, Madrid, Cátedra.

- (1980), Minerva seu de causis linguae Latinae, edición anastática cuidada por M. Breva Claramonte, $1980 \mathrm{~d}$.

Scaligero. J.C. (1597 (1540)), De causis linguae Latinae libri tredecim, Heidelberg, Petrus Santandreanus.

Scalise, S. (1981), «Introduzione», a N. A. Chomsky, Riflessioni sul linguaggio, Turin, Einaudi, 1981.

Stéfanini, J. (1976), "Jules César Scaliger et son De causis linguae Latinae», en Parret (1976), págs. 317-330.

Tovar, A. y de la Pinta Llorente, M. (1941), Procesos inquisitoriales contra Francisco Sánchez de las Brozas, Madrid, Consejo Superior de Investigaciones Científicas.

Uitti, K. D. (1969-1970), "Descartes and Port-Royal in two Diverse Retrospects", Romance Philology, 23, págs. 75-85.

Valla, L. (1550), Opera, Basilea.

Vasoli, C. (1968), La dialettica e la retorica dell'Umanesimo, Milán, Feltrinelli.

Viljamaa, T. (1976), "The Renaissance Reform of Latin Grammar», Annales Universitatis Turkuensis, Serja-Series B, Osa-Tom. 142, Turku, Turun Yliopisto.

Vives, J. L. (1947-1948), Obras completas, Madrid.

Wackernagel, J. (1950), Vorlesungen über Syntax, Basilea. 